\title{
POLÍTICA PÚBLICA DE APOIO AO ARTESANATO COMO ALTERNATIVA DE GERAÇÃO DE RENDA: INTEGRAÇÃO ENTRE BORDADEIRAS E EMPRESAS DE MODA
}

\section{PUBLIC POLICY TO SUPPORT HANDCRAFT AS AN ALTERNATIVE INCOME GENERATION: INTEGRATION OF EMBROIDERERS GROUPS AND FASHION COMPANIES}
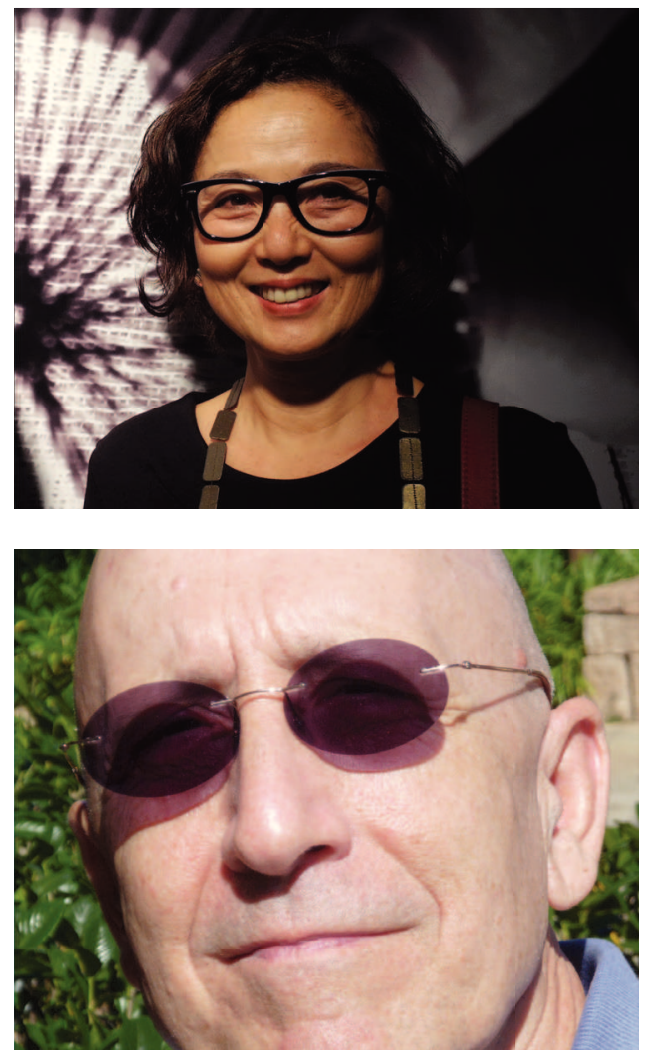

\section{Silvia Sasaoka}

Mestranda do Programa de Pós-Design da Universidade Estadual Paulista (UNESP). Campus de Bauru. Faculdade de Arquitetura, Artes e Comunicação (FAAC)

Bolsista da Capes.

silvia.sasaoka@gmail.com

\section{Olimpio José Pinheiro}

Pós-Doutor em Histoire et Theorie de l'Art na Ecole des Hautes Etudes en Sciences Sociales- EHESS, França; doutor e mestre em Sociologia pela Faculdade de Filosofia Letras e Ciências Humanas da Universidade de São Paulo-USP

Professor da Universidade Estadual Paulista - Júlio de Mesquita Filho na Faculdade de Arquitetura, Artes e Comunicação olympiop@faac.unesp.br

\section{RESUMO}

Este estudo trata de política de incentivo ao artesanato como alternativa de geração de renda de dois grupos de bordadeiras com pedraria no bairro do Itaim Paulista, na zona leste de São Paulo. Este artigo reflete sobre a viabilidade e a consolidação de estratégias a partir da criação de uma rede de apoio e intercâmbio entre confecções, estudantes e profissionais de design e moda. Constata-se que os métodos sistemáticos aqui apresentados exigem uma abordagem interdisciplinar como estratégia basilar de trabalho a fim de enfrentar os desafios da realidade social e econômica dos grupos envolvidos na câmara de animação econômica.

\section{PALAVRAS-CHAVE}

Moda. Artesanato. Políticas Públicas. 


\section{ABSTRACT}

The present study approaches the accomplishment of a public policy to support handcraft as an alternative income generation in two groups of embroiderers from eastern districts of São Paulo city - Itaim Paulista. This article considers the feasibility and the strenghtening of strategies for the development of a support network to promote the exchange and integration among clothing manufacturers, fashion students, designers and artisans. It is evident that the systematic method presented here require an interdisciplinary approach as fundamental strategy work in order to meet the challenges of social and economic reality of the groups involved in economic animation camera.

\section{KEYWORDS}

Fashion. Craft. Public Policy.

\section{INTRODUÇÃO}

Ao longo do ano de 2005, por meio de uma Câmara de Animação Econômica (CAE) - projeto de geração de trabalho e renda idealizado pela Subprefeitura Itaim Paulista com apoio da Secretaria do Desenvolvimento, Trabalho e Empreendedorismo da Prefeitura de São Paulo - foram identificadas diversas iniciativas, informais e formais, no ramo da confecção e do artesanato têxtil no bairro Itaim Paulista, localizado na zona leste da cidade. Esses pequenos empreendimentos constituíam um setor de relações econômicas capaz de contribuir para o fortalecimento de toda uma cadeia produtiva existente na região. Neste artigo, observa-se o prolongamento desta política pública através da atuação de seus consultores em campo, segundo a metodologia sistêmica, da incubação implantada para o desenvolvimento de uma câmara temática de confecção e artesanato. Os dados e registro deste projeto foram baseados no relatório "Desenho e implantação de projeto piloto de arranjos produtivos locais e suas oportunidades de geração de ocupação e renda" (DORT \& SASAOKA, 2011), realizado para estruturar rede que contribuísse para a animação econômica da região e articular em uma nova dinâmica para esta rede, gerando novo ponto de equilíbrio para este segmento têxtil na região, traduzida em maior nível de autonomia para os trabalhadores envolvidos, seja em termos de qualidade técnica de seus produtos ou de conscientização do valor de seu trabalho.

\section{IDENTIFICAÇÃO DO PÚBLICO-ALVO}

Em 2005, a Prefeitura de São Paulo implantou uma Câmara de Animação Econômica (CAE) na região do Itaim Paulista, por meio da subprefeitura local. O papel de animador dessa CAE foi desempenhado pela Straat Desenvolvimento e Projetos, consultoria especializada em design social.

Na primeira parte do trabalho, o animador fez o levantamento do público-alvo do projeto. Foi averiguada a existência de uma economia informal que sustenta o território e, não obstante, a condição precária da região. Constatou-se que há uma quantidade muito maior de empresas e empregados atuando na total informalidade do que mostravam os números contabilizados nos registros. Ao confrontar-se com os dados oficiais da RAIS onde, no caso do setor de confecção, havia no local 237 empresas cadastradas com CNPJ, com zero empregados (RAIS/2003), totalizando 536 postos de trabalho, verificou-se o universo da semiformalidade mesmo para estes poucos empreendimentos. Nas visitas técnicas constatou-se a existência de número muito maior de empresas e empregados, não contabilizados nos registros oficiais, na condição de total informalidade.

Feita essa identificação, no período entre 2005 e 2007 aplicou-se o conceito de Arranjos Produtivos Locais (APLs) como meio de fomento de atividades e inserção dos núcleos produtivos nessa dinâmica. De acordo com Brasil (s.d.), os APLs pressupõem que os diferentes atores locais (empresários individuais, sindicatos, associações, agências de desenvolvimento, entidades de capacitação, 
de educação, de crédito e de tecnologia etc.) "podem mobilizar-se e, de forma coordenada, identificar suas demandas coletivas por iniciativa própria ou por indução de entidades envolvidas com o segmento" (Brasil, s.d., p.1).

A implantação de uma metodologia sistêmica de incubação foi essencial para o desenvolvimento de uma câmara temática de confecção e artesanato têxtil no Itaim Paulista. Adotou-se a denominação Metodologia dos $6 \mathrm{Cs}$ - conscientização, caça-talentos, capacitação, crédito, cooperação, comercialização. Segundo Maturana (2004), a teoria sistêmica se baseia na compreensão de que os seres vivos são unidades discretas que operam como totalidades no espaço relacional, formando organismos. De modo semelhante, a conexão entre os pequenos grupos de produtores e bordadeiras formou uma rede de processos criativos capaz de atuar em parceria com a cadeia produtiva de confecções de roupas.

As ações no âmbito da câmara temática foram divididas em duas frentes. Uma delas abrangeu os empreendedores de pequenas confecções de roupas que já atuavam no território. A outra selecionou dois grupos de bordadeiras - um da Vila Cidade Kemel e outra da Vila Curuçá - formados a partir de laços comunitários. Neste estudo, observa-se a segunda frente.

\section{IDENTIFICAÇÃO DOS DOIS GRUPOS DE BORDADEIRAS E DE SUAS CARACTERÍSTICAS}

As informações coletadas no diagnóstico de potencialidades das bordadeiras foram obtidas por intermédio de bases oficiais (Relação Anual de Informações 2003 e Instituto Brasileiro de Geografia e Estatística) e não oficiais (entrevistas com as agentes comunitárias de saúde do Programa Saúde da Família, que mantinham contato direto com as bordadeiras).

As primeiras visitas técnicas ocorreram no posto de saúde do distrito do Itaim Paulista que atende quase todos os bairros do entorno da região do Itaim Paulista. Essas visitas foram coordenadas pelas agentes comunitárias de saúde. O posto já funcionava informalmente como ponto de encontro de mulheres que, sentadas em salas de espera por longas horas, preenchiam o tempo fazendo trabalhos manuais.

Diversas bordadeiras identificadas durante as visitas atuam como prestadoras de serviços de bordado com pedraria (miçangas, vidrilhos, cristais, pastilhas, fios metalizados etc.). Esse trabalho é feito artesanalmente usando linha e agulha; às vezes coloca-se o tecido em bastidores para bordar superfícies maiores. Em geral, os clientes dessas artesãs são lojas e confecções de roupas com enfoque em moda para cultura de massas, situadas nos bairros do Brás e do Bom Retiro, dois importantes polos de confecção e têxteis do Estado de São Paulo localizados na região central da capital.

As bordadeiras do Itaim Paulista formavam um público com baixa capacitação técnica e administrativa. Elas trabalhavam em seus próprios domicílios, atendendo a demandas esporádicas. No período em que foram realizadas as primeiras visitas, a renda média dessas artesãs girava em torno de 100 a 200 reais por mês, segundo entrevistas com as agentes comunitárias de saúde. Elas encontravam dificuldade no acesso regular à matéria-prima e aos processos de produção organizados. Essa deficiência era agravada pela falta de educação formal, de informação e de capital inicial. Todos esses fatores são um obstáculo à obtenção de um padrão adequado de qualidade, o que compromete a inserção de produtos no mercado formal do design e da moda.

Nas entrevistas com as bordadeiras, apurou-se a existência de um esquema de distribuição de peças em tecidos modelados e bordados estabelecido por três ou mais intermediários desde o local de origem (a Zona Leste) até a venda do produto em lojas de roupas de festa (na Região Central). Nesse esquema, os valores pagos pelo trabalho são quase simbólicos e limitam o potencial de geração de renda. Essa forma de organização, ainda que numa escala pequena, segundo Silva 
e Almeida (1997), se configura como uma proposta de subcontratação em que um contratante define as atividades de um contratado impondo expectativas de prazo, qualidade e custo, com critérios, estratégias e vínculos muito distantes de uma relação de parceria. Este modelo de gestão é fruto de um sistema econômico global que se reflete em todas as instâncias, de pequenas a grandes organizações. Superar os problemas dos pequenos produtores que oferecem serviços para grandes confecções é um desafio antigo. À medida que se aprofundam as contradições do atual modelo de desenvolvimento econômico globalizado, aponta Lastres e Cassiolato (2003), um dos maiores desafios específicos no Brasil e em outros países em desenvolvimento é a baixa escolaridade, qualificação e capacitação de seus cidadãos e trabalhadores.

Keller (2002) lembra que grandes proprietários de marcas de roupas internacionalmente conhecidas criam suas coleções nos países centrais onde atuam suas equipes de estilistas, deixam a manufatura para as pequenas confecções de países periféricos e distribuem seus produtos em lojas de departamento com valor agregado, como as peças de Calvin Klein. Os dois grupos de bordadeiras que participaram do projeto se assemelhavam por apresentar uma fronteira fluida entre a economia doméstica e a informalidade. Por outro lado, eles tinham natureza distinta e se encontravam em diferentes estágios de desenvolvimento.

O grupo da Cidade Kemel identificava-se como Cooperkemel - E embora o nome sugerisse, não se tratava de uma cooperativa formalizada, mas de um agrupamento informal. Eram 48 artesãs com razoável potencial técnico, tendo algumas delas experiência como bordadeiras com pedraria, costureiras ou fazedoras de fuxico (técnica artesanal que consiste em pequenas trouxas de tecido recortadas em círculo, alinhavadas e franzidas nas bordas, para a confecção de colchas, bolsas, tapetes etc.). Como se constatou que a qualidade de execução dos trabalhos variava demasiado, os produtos destas artesãs foram submetidos a uma avaliação técnica para qualificar a mesma em relação às expectativas do mercado de roupas de festa. Entre outros aspectos, foram avaliados: acabamento, técnicas de pontos de bordado e precisão das costuras.

O grupo da Vila Curuçá, também um agrupamento informal, era ligado a uma igreja local e identificava-se como Dorcas. Com a participação de 35 artesãs, surgiu como uma atividade de socialização, mas seu desenvolvimento acabou proporcionando a oportunidade de geração de renda para suas integrantes. A especialização dentro do grupo era baixa; a maior parte das artesãs era do tipo "faz tudo".

\section{VIABILIDADE E CONSOLIDAÇÃO DE ESTRATÉGIAS}

A partir do diagnóstico das condições de trabalho dessas bordadeiras, foi elaborado um único planejamento de ações estratégicas para os dois grupos, Cooperkemel e Dorcas. Essa etapa do projeto foi denominada Grupo de Trabalho de Confecção - Moda e Artesanato Têxtil.

Além de desenvolver a capacitação técnica das bordadeiras, o projeto da Câmara de Animação Econômica focou na criação de uma cultura de valorização do trabalho, fazendo com que as artesãs pudessem perceber seu potencial e sua condição de dependência do sistema de subcontratação.

O conceito de cooperação foi um dos elementos estruturantes da metodologia utilizada no Grupo de Trabalho de Confecção - Moda e Artesanato Têxtil. Através da conscientização da existência de formas alternativas de entrada ou reinserção no mercado, foi possível ampliar as oportunidades de geração de renda dessas bordadeiras. Ao longo do trabalho, o empreendedorismo e o associativismo foi incentivado.

As artesãs foram levadas a visitar as confecções parceiras e lojas de roupas de luxo e casual. Também se estabeleceram parcerias com empresas que trabalham com responsabilidade social na área da moda e design. As artesãs foram capacitadas a desenvolver os instrumentos necessários para sua inserção no mercado. Elas 
participaram de oficinas de aprimoramento técnico; de noções de desenho, composição de cores e formas; e de mercado, negociação e comercialização.

Ao mesmo tempo, realizou-se um trabalho de aproximação com confecções, lojistas, escolas de moda, estilistas e fornecedores de material para a progressiva manutenção de vínculos com o mercado, complementação do processo de aprendizagem e eventual formação de clientela.

A parceria estabelecida pela empresa Straat com o Atelier Marlene Brandão representou, para os grupos, um aprofundamento em seu universo profissional. A proprietária da empresa de moda, sua diretora de marketing e uma estilista realizaram palestras, oficinas de capacitação técnica e apresentação de roupas bordadas com pedraria e técnicas de ornamentação têxtil sobre tecidos finos.

Durante a capacitação foram usados como referência cerca de 30 vestidos do acervo do Atelier Marlene Brandão, depois doados às bordadeiras. Na Figura 1, algumas bordadeiras observam os vestidos. As Figuras 2 e 3 mostram parte do material apresentado durante as aulas. As bordadeiras fizeram uma visita guiada ao showroom da confecção de Marlene Brandão, no bairro do Itaim Bibi, na zona oeste de São Paulo, onde participaram de oficinas de aprimoramento técnico.

Figura 1. Bordadeira do Itaim Paulista com vestido Marlene Brandão.

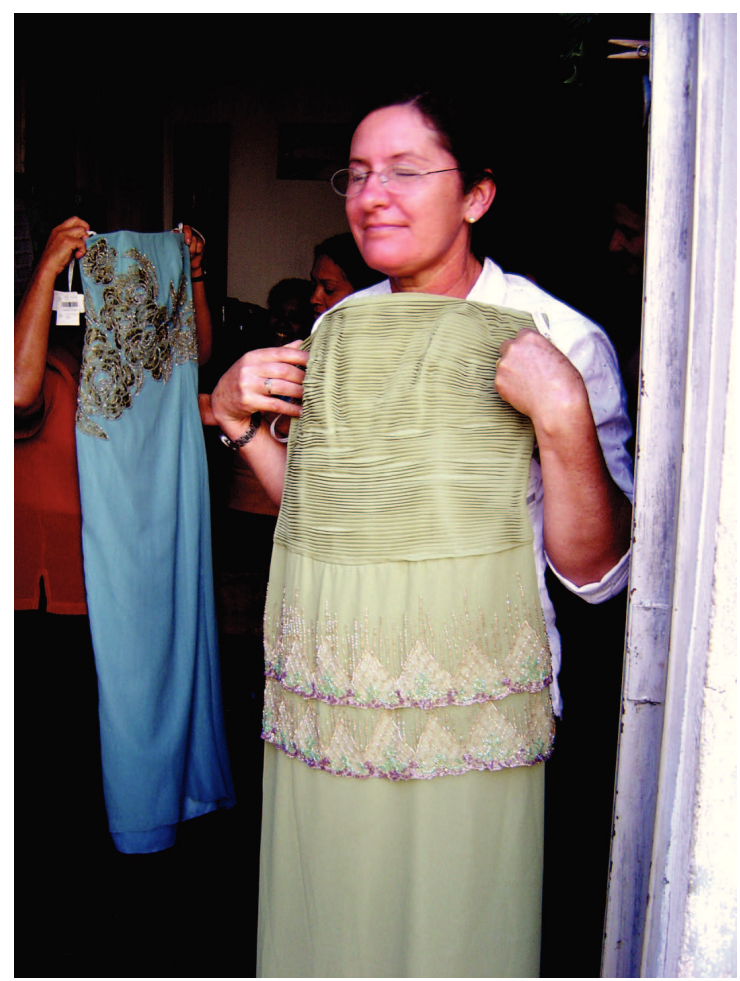

Fonte: acervo Straat, 2006. 
Figura 2. Mostruário de técnicas e tecidos de Marlene Brandão.

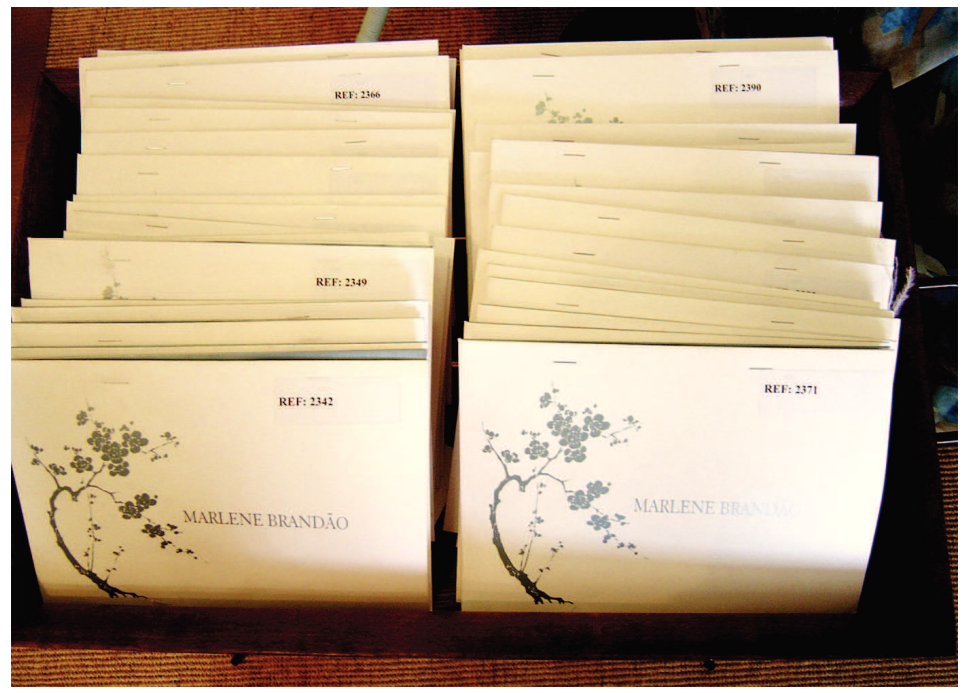

Fonte: acervo Straat, 2006.

Figura 3. Mostruário de técnicas e tecidos de Marlene Brandão.

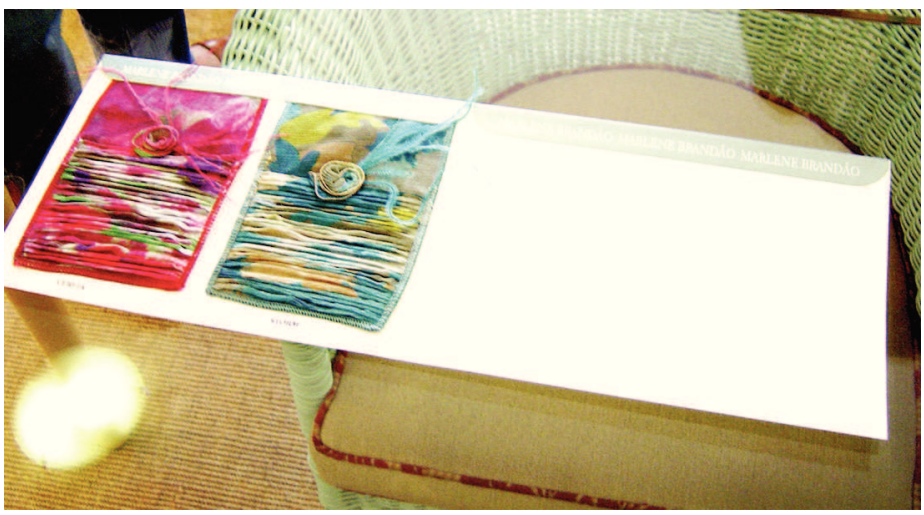

Fonte: acervo Straat, 2006.

\section{EDUCAÇÃO EM DESIGN EGRUPOS DE BORDADEIRAS}

Buscou-se também a contribuição e colaboração de estudantes de design com estas artesãs que visava estabelecer uma relação horizontal e transformadora para ambos os lados. Segundo destacam Eguchi e Pinheiro (2008) o designer tem em seu perfil a experiência do mundo globalizado e pouco conhece sobre culturas locais e populares. Esta troca de experiências técnicas e culturais vem atender às necessidades dos estudantes e das artesãs que, hoje em dia, enfrentam dificuldades frente aos novos paradigmas da produção, inovações infinitas de materiais, novos processos industriais, circulação de produtos e padrão de consumo, concomitantemente a um grande número de estudantes de design que procura um campo de atuação profissional que seja responsável e tenha função social.

Um grupo de estudantes do curso de Design da Faculdade de Arquitetura e Urbanismo da Universidade de São Paulo (FAU-USP) realizou uma oficina de comunicação visual para a criação de um nome e de uma identidade visual para os grupos. Durante o processo, o grupo Cooperkemel passou a se chamar Sol Nascente e o grupo Dorcas mudou seu nome para Lídia. As Figuras 4 e 5 mostram os cartões de visita criados a partir dessa oficina, já com os novos nomes. 
Figura 4. Cartão de visita do grupo Lídia. Identidade visual elaborada em parceria com estudantes de Design da FAU-USP.

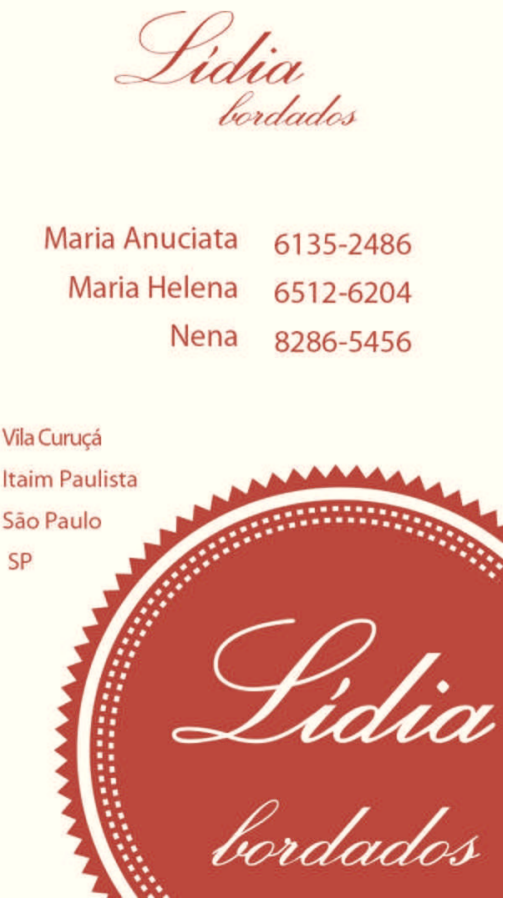

Fonte: acervo Straat, 2006.

Figura 5. Cartão de visita do grupo Sol Nascente. Identidade visual elaborada em parceria com estudantes de Desian da FAU-USP.
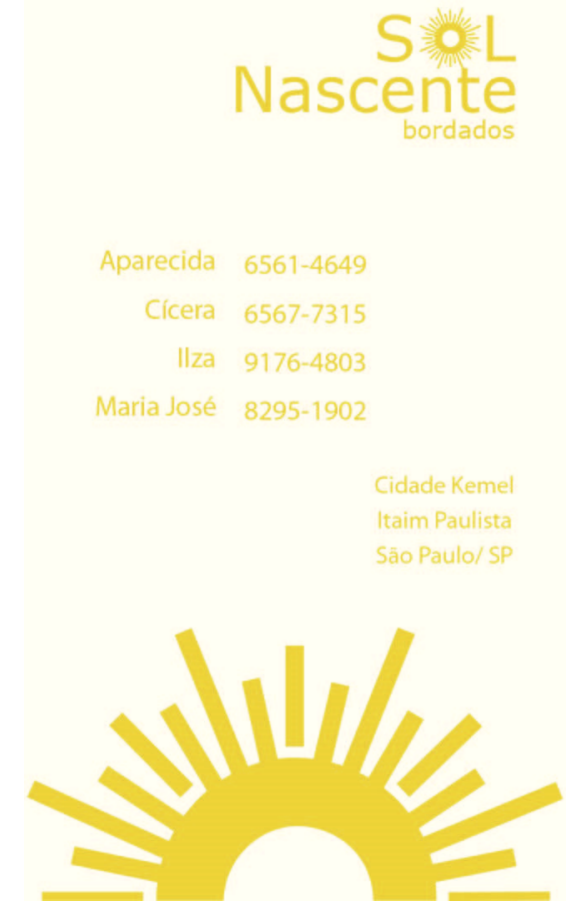

Fonte: acervo Straat, 2006. 
A Straat também formou uma parceria com o Instituto Europeo di Design de São Paulo, que criou um programa de design social para os alunos de seus cursos de Moda e Design de Interiores. Esses estudantes desenvolveram produtos a partir de visitas ao Sol Nascente e ao Lídia, como mostram as Figuras 6 e 7. Eles também fizeram um planejamento de trabalho para as bordadeiras, orientando-as quanto a formação de preço e desenvolvimento de produtos com base no tempo e nas técnicas empregadas.

As bordadeiras foram remuneradas pelos protótipos produzidos durante o processo. Os produtos e processos desenvolvidos com os estudantes do Instituto Europeo di Design de São Paulo foram apresentados na sede da escola, que fica no bairro de Higienópolis, na região central da capital paulista.

Figura 6. Cartaz da exposição dos produtos feitos pelo grupo Lídia em parceria com os estudantes do IED São Paulo.

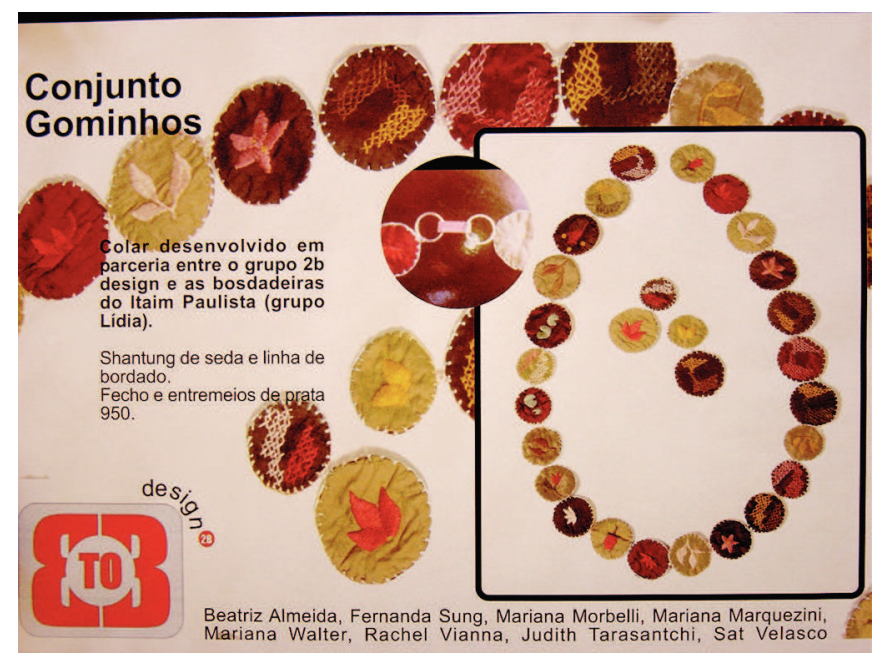

Fonte: acervo Straat, 2006.

Figura 7. Colar de seda bordada, criado pelo grupo Lídia em parceria com estudantes do IED São Paulo.

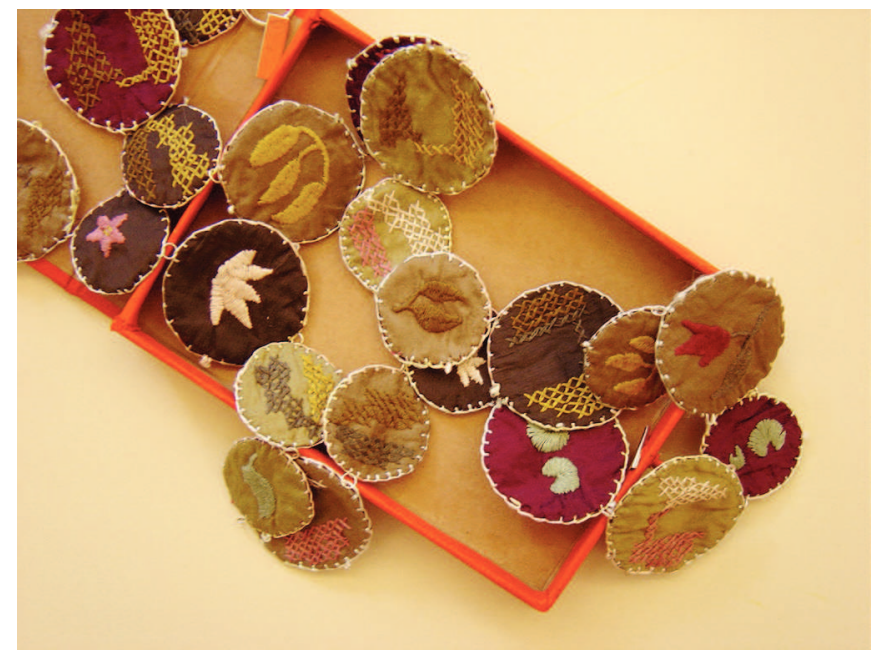

Fonte: acervo Straat, 2006.

Bonsiepe (2012) aponta a importância e a necessidade de aproximar o aprendizado universitário de problemas concretos a partir de práticas adquiridas em campo, como forma de acumular conhecimentos orientados segundo determinadas disciplinas científicas. 
A confluência entre duas realidades de saberes formais e informais sugere novos métodos de trabalho baseados em pensamentos transdisciplinares para a busca de soluções que correspondam a expectativas de ambos os lados dos participantes de um projeto. A criatividade segundo Weschler (1993) é um elemento de impacto em todas as áreas do conhecimento e a autora afirma que, Paul Torrence, grande estudioso e pesquisador na área da educação explicou que a criatividade está relacionada à capacidade do indivíduo de reconhecer e lidar com problemas, falhas, deficiências, dispondo ainda de habilidade de formular e responder a hipóteses que podem atender a necessidades sociais presentes.

Moura (2011) aponta que é necessário refletir a respeito das possibilidades de novos métodos e metodologias projetuais do design no contexto da contemporaneidade desde que o mesmo propõe a conexão entre as questões culturais, sócio-políticas e econômicas. Para Loschiavo dos Santos (2013), a racionalidade das Ciências Humanas volta-se à compreensão dos fenômenos sociais. Já as Ciências Sociais Aplicadas procuram compreender, problematizar e intervir na realidade. Esse encadeamento entre estudo e prática complementa a formação humanista do designer - bem como a do arquiteto e do urbanista. As disciplinas teórico-críticas, nesse caso, não são auxiliares; elas aumentam o grau de compreensão da realidade e da própria atuação do profissional.

\section{CONSIDERAÇÕES FINAIS}

Os resultados do projeto da Câmara de Animação Econômica com foco na confecção e no artesanato foram bem-sucedidos, segundo os pressupostos estabelecidos inicialmente. As atividades desenvolvidas dentro da comunidade, sem burocracia, contribuíram positivamente para aproximar as artesãs e os consultores técnicos. Por outro lado, muitas vezes a participação das artesãs foi prejudicada por sua dificuldade de conciliar as atividades domésticas com as profissionais, interferindo no processo produtivo.

Foram implementadas novas formas de organização do trabalho coletivo dentro dos grupos. Observou-se um aumento no grau de desenvolvimento técnico, pessoal, de comprometimento e de autoestima. O Sol Nascente, por exemplo, teve a iniciativa de realizar uma pesquisa de mercado no seu próprio bairro para lançar uma linha de produtos natalinos cujas vendas foram realizadas com sucesso.

Através das parcerias com profissionais, estudantes e empresas de moda e das visitas guiadas das bordadeiras por outros bairros da cidade, foi possível diminuir o isolamento dessa população, promovendo a integração de diferentes realidades socioculturais. A qualidade técnica dos bordados melhorou sensivelmente. A conexão dos grupos com redes comerciais se configurou como fator importante para os negócios. As artesãs tomaram conhecimento sobre as exigências do mercado de roupas de festa e decoração, e discutiram objetivos e características mercadológicas com a definição de novo nome e identidade visual.

A geração de renda foi viabilizada já durante a realização do programa de capacitação, por meio de pequenos pedidos realizados pelos parceiros do projeto. A valorização do próprio trabalho foi um dos principais aspectos, como forma de ampliar o empoderamento nas negociações com os compradores.

No pacto construído a partir da facilitação da Câmara de Animação Econômica, observa-se diversos pontos de estruturação das ações: que a aproximação entre os diversos atores da cadeia produtiva é uma estratégia basilar para a animação econômica em nível local; desafios técnicos, de projeto e gestão e comerciais precisam ser equacionados em função das características e necessidades dos grupos locais; e a partir desse desenvolvimento inicial alcançar um nível de capacitação e de competência técnica e administrativa que corresponda aos padrões de qualidade exigidos pelo mercado global. Neste estudo busca-se também demonstrar o quanto é necessário, em tais ações e políticas públicas, construir um código de conduta para as negociações, a fim de evitar a exploração do trabalho artesanal e valorizar o artesanato como uma característica não só econômica, mas cultural de uma região. 


\section{NOTAS}

[1] Animador é o termo técnico usado para designar o responsável pela interface metodológica do trabalho; a ele compete a localização e o diagnóstico dos produtores locais, assim como sua integração e encaminhamento às políticas públicas disponíveis, a oferta de capacitação customizada, o processo de empoderamento e a facilitação das relações socioeconômicas na cadeia produtiva. (DORT; SASAOKA, 2011)

\section{REFERÊNCIAS}

BONSIEPE, Gui. Design como prática de projeto. São Paulo: Blucher, 2012.

BRASIL. INMETRO (Org.). O Inmetro e os arranjos produtivos locais [s.d.]. Disponível em http://www.inmetro.gov.br/apls/apresentacao.asp. Acesso em 01/06/2015.

DORT, Anton; SASAOKA, Silvia. Desenho e implantação de projeto piloto de arranjos produtivos locais e suas oportunidades de geração de ocupação e renda. Carta Acordo 407-1564 - PNUF - SMTRAB - FESPSP. Diário Oficial, São Paulo, p. 192-197, 05 de novembro de 2011.

EGUCHI, Haroldo C.; PINHEIRO, Olimpio J. Design versus artesanato. Anais do $8^{\circ}$ Congresso Brasileiro de Pesquisa e Desenvolvimento em Design, 2008. Disponível em www.maxwell.vrac.puc-rio.br/17390/17390.pdf. Acesso em 15/06/2015.

KELLER, Paulo F. Capitalismo global e novas formas de organização na cadeia têxtil-confecção: uma revisão bibliográfica. Enfoques, Rio de Janeiro, v. 1, n. 1, p. 46-117, 2002.

LASTRES, Helena Maria M.; CASSIOLATO, José E. Novas Políticas na Era do Conhecimento: o foco em arranjos produtivos e inovativos locais. Revista Parcerias Estratégicas, 2003. Disponível em http://www.ie.ufrj.br/redesist/Artigos/ LasCasParcerias.pdf. Acesso em 10/06/2015.

LOSCHIAVO DOS SANTOS, Maria. C. Reflexões sobre design e humanismo no mundo contemporâneo. Cadernos de Estudos Avançados em Design, Barbacena, v. 7. 2013.

MATURANA, Humberto R.; DAVILA, Ximena. Ética e desenvolvimento sustentável: caminhos para a construção de uma nova sociedade. Psicol. Soc., v. 16, n. 3, p. 102-110, 2004. Disponível em http://www.scielo.br/scielo. php?script=sci_arttext\&pid=S0102-71822004000300013\&lng=en\&nrm=iso. Acesso em 04/06/2015.

MOURA, Mônica. Interdisciplinaridades no Design Contemporâneo. In: Menezes, Marizilda; Paschoarelli, Luis Carlos; Moura, Mônica. (Org.). Metodologias em Design: Inter-Relações. 1ed. São Paulo: Estação das Letras e Cores, 2011, v. 1, p. 274-290

SILVA, R. A. R. da; ALMEIDA, M. C. de. Terceirização e quarteirização: indicativos estratégicos para implementação. In: Encontro Anual da Associação Nacional de Pós-Graduação e Pesquisa em Administração - ENANPAD, Rio Das Pedras, 1997.

WECHSLER, Solange M. Criatividade: descobrindo e encorajando. Campinas: Editora Psy, 1993. 


\section{Silvia Sasaoka}

É mestranda pelo Programa de Pós-Design da Universidade Estadual Paulista (UNESP). Faculdade de Arquitetura, Artes e Comunicação (FAAC). É Bolsista da Capes (2015). Licenciada em Educação Artística/ Arte Educação (2000) pela Faculdade de Belas Artes de São Paulo - FEBASP. Participa do grupo de Pesquisa em Design Contemporâneo: sistemas, objetos e cultura da Unesp liderado pela Prof. Dra. Mônica Moura. Possui publicações em anais de congressos, revista e livro, como Craftwork in Brazil: Dialogues with Tradition and Contemporaneity (Artigo-Conferência 8th Senses \& Sensibility 2015, Lisboa); A Renda Artesanal e suas aplicações na Moda (Artigo-10 ${ }^{\circ}$. Colóquio de Moda, RS); O Processo Criativo: do artesanato ao design (Artigo- $2^{\circ}$ Congresso em Estética e História da Arte, 2004. USP); Grafismos no Projeto Botuafrica: um diálogo intercultural (Periódico científico- Revista Educação Gráfica 2014); Design Contemporâneo: pesquisas interdisciplinares (Capítulo do livro- Interação: Panorama das Pesquisas em Design, Arquitetura e Urbanismo, 2015). Consultora no Artesol- Artesanato Solidário (2002/2012), coordenadora de projetos no Museu A Casa - de Artes e Artefatos Brasileiros, atual Museu do Objeto Brasileiro em São Paulo (1998/2002).

Desde 2010 atua como coordenadora no Instituto Botucatu/SP.

\section{Olimpio José Pinheiro}

Graduado em Artes Plásticas pela Escola de Comunicações e Artes (ECA) da Universidade de São Paulo (USP). Mestrado e Doutorado: em Sociologia (da Arte), pela Faculdade de Filosofia, Letras e Ciências Humanas (FFLCH), na (USP). PósDoutorado: em História e Teoria da Arte na École des Hautes Études en Sciences Sociales (EHESS), no Centre de Histoire et Theorie de l'Art (CEHTA), Paris. ExProfessor efetivo da Universidade Estadual de Londrina (UEL), Paraná. Professor convidado da Universidade Fernando Pessoa (UFP), Porto, Portugal. Atualmente: professor efetivo da Universidade Estadual Paulista (UNESP) na Faculdade de Arquitetura, Artes e Comunicação (FAAC) no curso de graduação em Artes Visuais e Design e na pós-graduação: Design (Mestrado e Doutorado). Bolsas: do CNPq (Mestrado e Doutorado); e da Capes (Doutorado e Pós-Doutorado). Do conselho científico dos periódicos Revista da UFP, Universidade Fernando Pessoa, Portugal; Revista: Agalia, Espanha; Revista: Cadernos de Campo, FFLCH, USP; entre outros. Livros publicados (entre outros): Arte ou Design? A Azulejaria Colonial na Era da Hipermedia (em preparação). São Paulo: 2014; Prefácio a Azulejaria barroca do claustro de São Francisco de Salvador: Interpretação simbólica. In Dugnani, P.; A herança simbólica na Azulejaria barroca; Os painéis do Claustro da Igreja de São Francisco da Bahia. U.P.Mackenzie, 2012; O Azulejo Colonial luso-brasileiro: uma leitura plural. In Tirapeli, P. (Org). Arte Sacra Colonial; Barroco Memória Viva. São Paulo: EdUNESP, 2001; Olympio. Azulejos da Bahia. Rio de Janeiro: Kosmos, 1986. 